Entdeckung eines Cometen (c 1877).

Telegraphische Depesche der K. Akademie d. W. in Wien an den Herausgeber. Comet Borrelly. 14. April $9^{\mathrm{h}} 30^{\mathrm{m}}$ Marseille. $x=16^{\circ} 30^{\prime} . \quad P=34^{\circ} 56^{\prime} .+120^{\circ} ;-50^{\circ}$ rund, hell, Kern.

Beobachtung des Cometen b 1877 (Winnecke).

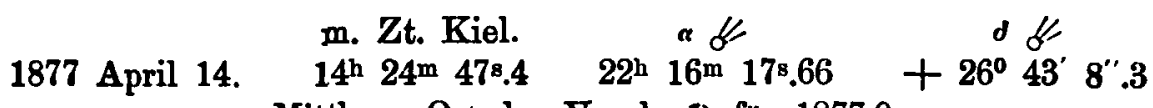
Mittlerer Ort des Vergl. für 1877.0.

Kiel, 1877 April 17. W. $22^{\mathrm{h}} .378 . \quad \alpha=22^{\mathrm{h}} 18^{\mathrm{m}} 8^{\mathrm{8}} .53 \quad \delta=+26^{\circ} 44^{\prime} 0^{\prime \prime} .8$

C. F. W. Peters.

\title{
Beobachtung des Cometen Winnecke auf der Sternwarte zu Göttingen.
}

Göttg. April 14. $15^{\mathrm{h}} 22^{\mathrm{m}} 28^{\mathrm{s}}$ M. Z.

a $\&=22^{\mathrm{h}} 16^{\mathrm{m}} 16^{\mathrm{s}} .47 . \quad$ of $\&^{\prime}=26^{\circ} 46^{\prime} 57^{\prime \prime} .7$

aus zwei zweiseitigen Vergleichungen mit $\mathbf{4 4 2 8}$ der Bonner Durchmusterung, also vier Vergleichungen.

Der für den Vergleichstern angenommene scheinbare Ort ist:

$a=22^{\mathrm{h}} 19^{\mathrm{m}} 24^{\prime \prime} .74, \delta=26^{\circ} 36^{\prime} 52^{\prime \prime} .5$.

W. Klinkerfues.

\section{Beobachtung des Cometen b 1877.}

Den von Professor Winnecke entdeckten Cometen habe ich wie folgt beobachtet:

1877 April 8. 15 $52^{\mathrm{m}} 44^{\mathrm{B}}$ mittl. Zeit Berlin.

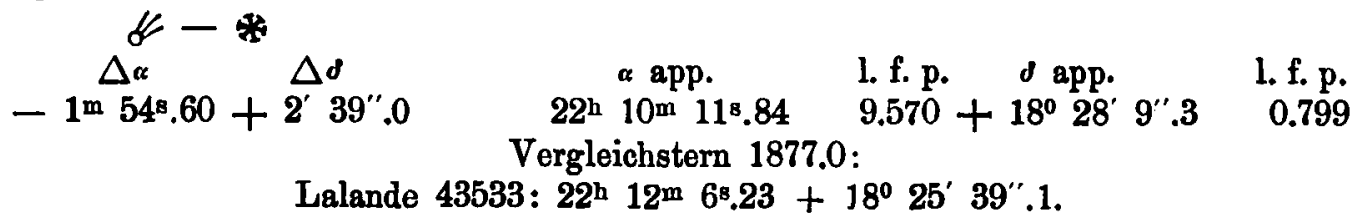

Berlin 1877 April 10.

V. Knorre.

1877

\section{Beobachtungen der Cometen $b$ und c 1877.}

April 14. $15^{\mathrm{h}} 4^{\mathrm{m}} 57^{\mathrm{s}} \mathrm{m}$. Zt. Berlin.

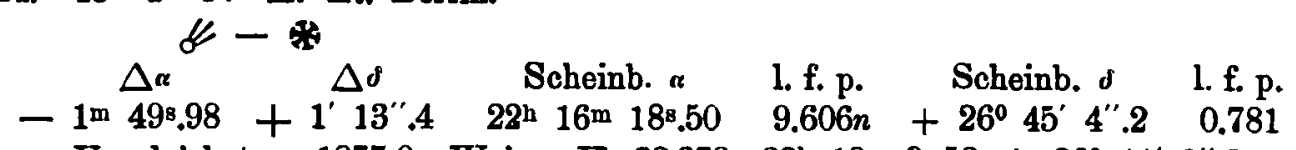

Vergleichstern 1877.0 : Weisse H. 22.378: $22^{\text {h }} 18^{\mathrm{m}} 8^{\mathrm{s}} .53+26^{\circ} 44^{\prime} 0^{\prime \prime} .8$

April 15. $9^{\mathrm{h}} 59^{\mathrm{m}} 20^{\mathrm{s}} \mathrm{m}$. Zt. Berlin. $\& 4$ e 1877 Borrelly.

$$
+0^{\mathrm{m}} 44^{\mathrm{s}} .69+1^{\prime} 54^{\prime \prime} .51^{\text {h }} 14^{\mathrm{m}} 13^{\mathrm{s}} .529 .428+55^{\circ} 47^{\prime} 46^{\prime \prime} .70 .905
$$

Vergleichstern 1877.0: $\frac{\text { Arg. Oel. }+ \text { Rumk }}{2}: 1^{\text {h }} 13^{\mathrm{m}} 30^{\mathrm{s}} .41+55^{\circ} 45^{\prime} 48^{\prime \prime} .4$

Berlin 1877 April 16.

V. Knorre. 